\title{
Synthesis of Improved Catalytic Materials for High-Temperature Water-gas Shift Reaction
}

\author{
Zara P. Cherkezova-Zheleva*, Katerina L. Zaharieva, Ivan B. Ivanov, Vasko D. Idakiev, Ivan G. Mitov
}

\author{
Institute of Catalysis, Bulgarian Academy of Sciences, Acad. G. Bonchev Str., Bldg. 11, Sofia 1113, Bulgaria \\ * Corresponding author's e-mail address: zzhel@ic.bas.bg
}

RECEIVED: November 9, 2015 * REVISED: December 9, 2015 * ACCEPTED: December 10, 2015

THIS PAPER IS DEDICATED TO DR. SVETOZAR MUSiĆ ON THE OCCASION OF HIS 70 Th BIRTHDAY

\begin{abstract}
In this investigation, we report the preparation and characterization of Co-, $\mathrm{Cu}$ - and Mn-substituted iron oxide catalytic materials supported on activated carbon. Co-precipitation method and low temperature treatment were used for their synthesis. The influence of chemical composition, stoichiometry, particle size and dispersity on their catalytic activity was studied. Samples were characterized in all stages of their co-precipitation, heating and spend samples after catalytic tests. The obtained results from room and low temperature Mössbauer spectroscopy were combined with analysis of powder X-ray diffraction patterns (XRD). They revealed the preparation of nano-sized iron oxide materials supported on activated carbon. Relaxation phenomena were registered also for the supported phases. The catalytic performance in the water-gas shift reaction was studied. The activity order was as follows: $\mathrm{Cu}_{0.5} \mathrm{Fe}_{2.5} \mathrm{O}_{4}>\mathrm{Co}_{0.5} \mathrm{Fe}_{2.5} \mathrm{O}_{4}>\mathrm{Mn}_{0.5} \mathrm{Fe}_{2.5} \mathrm{O}_{4}$. Catalytic tests demonstrated very promising results and potential application of studied samples due to their cost-effective composition.
\end{abstract}

Keywords: nano-sized substituted magnetites, activated carbon, water-gas shift reaction.

\section{INTRODUCTION}

$\mathbf{T}$ HE water-gas shift reaction (WGSR) is an important industrial reaction for removing $\mathrm{CO}$ and upgrading the purity of $\mathrm{H}_{2}$ for fuel cell applications, ammonia synthesis, and selective hydrogenation processes. ${ }^{[1-5]}$ The reaction is: $\mathrm{CO}+\mathrm{H}_{2} \mathrm{O} \leftrightarrow \mathrm{CO}_{2}+\mathrm{H}_{2} ; \Delta H_{298 \mathrm{~K}}=-41 \mathrm{~kJ} \mathrm{~mol}^{-1}$. In recent years, much attention has been paid to exploration the possibility of using bulk and supported nanocatalysts for WGSR and understanding the fundamental aspects related to the nature of active sites, reaction mechanisms and catalyst deactivation. ${ }^{[1]}$ From the WGSR thermodynamic is well known that at high temperatures the conversion is equilibrium limited. On other hand low temperature shift is kinetically limited. This requires the use of two catalysts in two successive stages with cooling between them to achieve the desired degree of CO conversion. ${ }^{[1-5]}$ So the WGSR is conducted industrially over two catalysts, which operate in different temperature regimes. The magnetite is the main active phase of the high temperature WGSR. However, the conventional high-temperature WGSR catalysts are based on oxides of iron and chromium to improve their stability. On the other hand it is crucial to identify alternative promoters and to develop a $\mathrm{Cr}$-free catalyst because of its very high toxicity. $\mathrm{Co}, \mathrm{Cu}$ and $\mathrm{Mn}$ are proposed as the promising candidates on the basis of number of studies. ${ }^{[2-4]}$ The hightemperature shift catalyst operates at $350-450{ }^{\circ} \mathrm{C}$. The second catalyst consists of oxides of copper, zinc and aluminum. It is labeled the low-temperature shift catalyst and operates at $200-250{ }^{\circ} \mathrm{C}$. Although the two mentioned conventional catalysts are used industrially in the production of $\mathrm{H}_{2}$ for ammonia synthesis, they have major drawbacks that make them unsuitable for transportation applications. Both the low- and the high-temperature catalysts must first be "activated" before being used.

Magnetite and substituted magnetite of general formula $\mathrm{Me}_{x} \mathrm{Fe}_{3-x} \mathrm{O}_{4}, 0 \leq x \leq 1$ (where Me denotes a divalent cation) are technologically important materials for microwave, electronic, magnetic storage devices and as catalysts for industrial and environmental application. ${ }^{[6-9]}$ Magnetite $\left(\mathrm{Fe}_{3} \mathrm{O}_{4}\right)$ and substituted magnetite-type ferrites $-\mathrm{Me}_{0.5} \mathrm{Fe}_{2.5} \mathrm{O}_{4}$ ( $\mathrm{Me}=\mathrm{Mn}^{2+}, \mathrm{Co}^{2+}, \mathrm{Cu}^{2+}$, etc. $)$ are members of solid solution series, which permits the synthesis of samples with various magnetic properties and various degree of electron 
delocalization. They demonstrate good gas sensing properties and catalytic activity in various catalytic processes, such as WGSR, complete oxidation of waste gases, oxidative dehydrogenation of hydrocarbons, decomposition of alcohols etc. It was found that the properties of nanosized spinel ferrites differ strongly from those of the corresponding bulk materials. ${ }^{[6-9]}$ It was found that partially substituted magnetites $\left(\mathrm{Me}_{x} \mathrm{Fe}_{3-x} \mathrm{O}_{4}\right)$ have better catalytic behavior than the $\mathrm{MeFe}_{2} \mathrm{O}_{4} \cdot{ }^{[2-3]} \mathrm{Up}$ today, much attention has been paid to the preparation of such nanocrystalline bulk and supported materials, because of difficulty of their synthesis procedures and special techniques used. Various synthetic methods have been developed to synthesize oxide nanoparticles, among them co-precipitation, thermal decomposition, sol-gel, microemulsion and other techniques. ${ }^{[2-3,6-9]}$ It was established that the degree of crystallinity, particle size and particle morphology of oxide nanoparticles are strongly dependent on the method used for their preparation. In this regard the heterogeneous catalyst for water-gas shift reaction should have a number of characteristics.

The aim of this investigation is to prepare nano-sized substituted magnetite $\mathrm{Cu}_{0.5} \mathrm{Fe}_{2.5} \mathrm{O}_{4}, \mathrm{Mn}_{0.5} \mathrm{Fe}_{2.5} \mathrm{O}_{4}$ and $\mathrm{Co}_{0.5} \mathrm{Fe}_{2.5} \mathrm{O}_{4}$ materials supported on activated carbon from peach stones appropriate for high temperature WGSR. Physicochemical and catalytic properties of samples were also studied.

\section{EXPERIMENTAL}

The substituted magnetite-type materials with different chemical composition were synthesized by co-precipitation method. All materials $\mathrm{Cu}_{0.5} \mathrm{Fe}_{2.5} \mathrm{O}_{4}, \mathrm{Mn}_{0.5} \mathrm{Fe}_{2.5} \mathrm{O}_{4}$ and $\mathrm{Co}_{0.5} \mathrm{Fe}_{2.5} \mathrm{O}_{4}$ were supported on activated carbon (AC) from peach stones. The initial compounds were: $\mathrm{Fe}\left(\mathrm{NO}_{3}\right)_{3} \cdot 9 \mathrm{H}_{2} \mathrm{O}$ (Alfa Aesar, $99.99 \%$ ) and $\mathrm{Cu}\left(\mathrm{NO}_{3}\right)_{2} \cdot 3 \mathrm{H}_{2} \mathrm{O}$ (Merck, $99.99 \%$ ), $\mathrm{Mn}\left(\mathrm{NO}_{3}\right)_{2} \cdot 4 \mathrm{H}_{2} \mathrm{O}$ (Alfa Aesar, $99.9 \%$ ) or $\mathrm{Co}\left(\mathrm{NO}_{3}\right)_{2} \cdot 6 \mathrm{H}_{2} \mathrm{O}$ (GPR Rectapur/VWR Prolabo Chemicals, $99.99 \%$ ) and sodium hydroxide as precipitant (Sigma-Aldrich, pellets, $\geq$ $97 \%)$. The calcination procedure of co-precipitated precursors was performed for 3 hours at $400{ }^{\circ} \mathrm{C}$ in nitrogen gas flow. Materials were denoted as: Sample A - $\mathrm{Co}_{0.5} \mathrm{Fe}_{2.5} \mathrm{O}_{4} / \mathrm{AC}$, Sample $\boldsymbol{B}-\mathrm{Cu}_{0.5} \mathrm{Fe}_{2.5} \mathrm{O}_{4} / \mathrm{AC}$ and Sample $\boldsymbol{C}-\mathrm{Mn}_{0.5} \mathrm{Fe}_{2.5} \mathrm{O}_{4} / \mathrm{AC}$. Precursors $A, B$ and $C$ are materials before heating, i.e. coprecipitated Samples $\boldsymbol{A}, \boldsymbol{B}$ and $\boldsymbol{C}$ before heating.

Powder X-ray diffraction (XRD) patterns were collected using a TUR-M62 apparatus (Germany) with Co and $\mathrm{Cu} \mathrm{K} \alpha$ radiation. Data interpretation was carried out using the JCPDS database. Average crystallite sizes and microstrains were determined from Williamson-Hall diagram. ${ }^{[10]}$
The Mössbauer spectra were obtained at room temperature and liquid nitrogen temperature with a spectrometer Wissenschaftliche Elektronik GMBN, Germany working in a constant acceleration mode using ${ }^{57} \mathrm{Co} / \mathrm{Rh}$ (activity $\approx 50$ $\mathrm{mCi}$ ) source and $\alpha$-Fe standard. The parameters of hyperfine interaction - isomer shift (IS), quadrupole splitting (QS) and magnetic hyperfine field $\left(H_{\text {eff }}\right)$ as well as the line widths (FWHM) and the relative spectral area $(G)$ of the partial components of the spectra were determined.

The water-gas shift activity was measured in a flow reactor at atmospheric pressure. The samples are tested in the temperature range of $170-350^{\circ} \mathrm{C}$. The applied experimental conditions were: catalyst bed volume $0.5 \mathrm{~cm}^{3}$, space velocity $4000 \mathrm{~h}^{-1}$, partial pressure of water vapor $31.1 \mathrm{kPa}$ and $4.46 \mathrm{vol}$. \% $\mathrm{CO}$ in argon as reactant gas mixture. The $\mathrm{CO}$ content at the reactor outlet was analyzed on an "URAS3G" (Hartmann \&Braun AG) gas analyzer. The catalytic activity was expressed in $\%$ of $\mathrm{CO}$ conversion. The catalytic activity was conducted after establishing of the steady-state conversion conditions for corresponding temperature.

\section{RESULTS AND DISCUSSION}

The powder X-ray diffraction and Mössbauer spectroscopy analysis of prepared samples were performed. The structure, phase composition and dispersity were determined before and after WGSR catalytic tests. In all materials the recorded powder X-ray diffractograms show the characteristic peaks of the activated carbon and the broad and lowintensity peaks of respective spinel phase (Figure 1). So the spinel synthesis starts on the precipitation process. Additional phases are not presented in XRDs. However all samples were heated up to $400{ }^{\circ} \mathrm{C}$ in order to complete the phase formation and crystallization process and to avoid temperature changes of materials during the catalytic reaction (maximal reaction temperature $-350{ }^{\circ} \mathrm{C}$ ). After thermal treatment of $\mathrm{Co}$ - and $\mathrm{Cu}$-containing catalysts (Samples $A$ and $B$ ) hematite phase was also registered as it can be seen on Figure 2. Presented amorphous halo peaks, as well as broad and low-intensity diffraction peaks confirm the high dispersion of supported phases especially for $\mathrm{Mn}$-contained ferrite spinel (Sample C). According to WilliamsonHall diagram the mean crystallite size can be estimated about 10-12 nm for spinel phases and below $18 \mathrm{~nm}$ for hematite showing the nanometric size for all supported active phases in Samples A and B. The mean crystallite size of Sample $C$ is lower. Relative weights of supported spinel ferrite phase vs. hematite phase obtained from X-ray powder diffraction data are $84 \%: 16 \%$ in Sample A, $65 \%: 35 \%$ in Sample B and $100 \%: 0 \%$ in Sample C.

In case of X-ray diffraction peaks with low intensities and broad background, as well as the special effects in XRD 


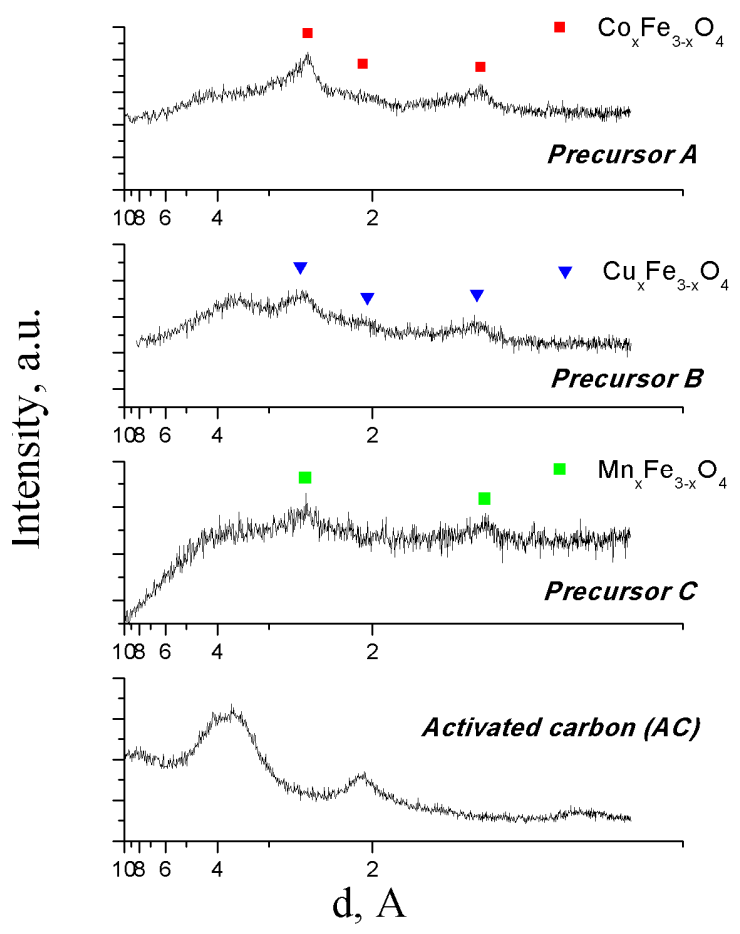

Figure 1. Powder XRD spectra of precursor materials and used support (activated carbon).

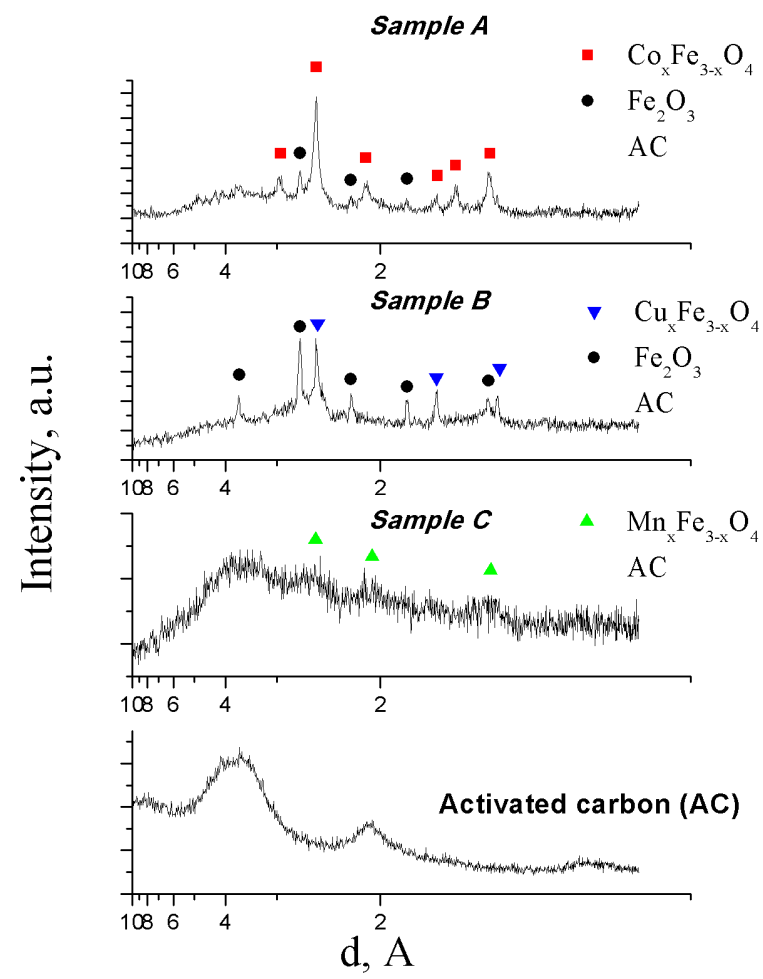

Figure 2. Powder XRD spectra of prepared catalytic materials and used support (activated carbon). were observed (the case of Mn-contained materials) another method should be used in order to register the composition of amorphous phases also. For iron-contained samples very appropriate is the analysis with Mössbauer spectroscopy.

Mössbauer spectra of materials at room temperature (RT) and liquid nitrogen temperature (LNT) were recorded. They were shown on Figures 3-5. Spectra evaluation was done by the CONFIT program as an optimal fit of component superposition. In all three cases the Mössbauer spectra of precursors of Samples A, B and C (unheated materials) represent superposition of doublet-type lines only (not shown). Their analysis shows that these doublet components belong probably to ferrite spinel phase with socalled superparamagnetic (SPM) behavior due to thermally activated reversals of the particles magnetization moments. ${ }^{[11-14]}$ The resulting effect is the collapse of magnetic hyperfine structure in the Mössbauer spectra. After heating of materials only $\mathrm{Mn}$-contained sample preserve this doublet type spectrum (Figures 3-5). This confirms the highest dispersion of supported phase in Sample C. The spectra of Samples A and B registered the presence of sextet and doublet components. Calculated hyperfine parameters show the presence of tetrahedrally and octahedrally coordinated iron ions in spinel phase, $\mathrm{Fe}^{3+}$ in hematite phase and different quantity of paramagnetic component. However, the values of sextet hyperfine fields are smaller than the characteristic ones for the bulk materials which can be explained by nanodimensional crystallite size and so-called collective magnetic excitation behavior phenomenon (CME). ${ }^{[13-14]}$ In order to investigate the origin of doublet lines in both cases their LNT Mössbauer spectra are obtained and the RT spectra are completely resolved for Samples $A$ and $B$ (Figures 3-5). The evaluation of spectra confirmed the analysis of RT spectra. Their calculated hyperfine parameters have characteristic values for spinel and hematite phase but the $H_{\text {eff }}$ values of sextet components are lower than those of bulk materials (Table 1). Sample $\mathrm{C}$ preserve doublet components in LNT spectrum and only $20 \%$ is magnetically splitted. LNT spectrum of the Sample $C$ is a case of not completely resolved spectrum when the temperature is close, but not lower than so-called blocking temperature where a magnetically split subspectra will be registered. According to the literature data, the mean size of supported oxide particles presented as SPM and CME components is about 3-5 nm and bellow $12 \mathrm{~nm}$, respectively. ${ }^{[11-14]}$ All fitted parameters of the Mössbauer spectra are given in Table 1.

The WGSR catalytic performance of the samples was studied (Figure 6). The highest catalytic activity among the tested catalysts was registered by copper-containing sample. The order of WGSR catalytic activity was followed: $\mathrm{Cu}_{0.5} \mathrm{Fe}_{2.5} \mathrm{O}_{4} / \mathrm{AC}>\mathrm{Co}_{0.5} \mathrm{Fe}_{2.5} \mathrm{O}_{4} / \mathrm{AC}>\mathrm{Mn}_{0.5} \mathrm{Fe}_{2.5} \mathrm{O}_{4} / \mathrm{AC}$. 
After the registration of promise catalytic results of the investigated materials we studied the spent catalysts to obtain the formed phases which are active in reaction

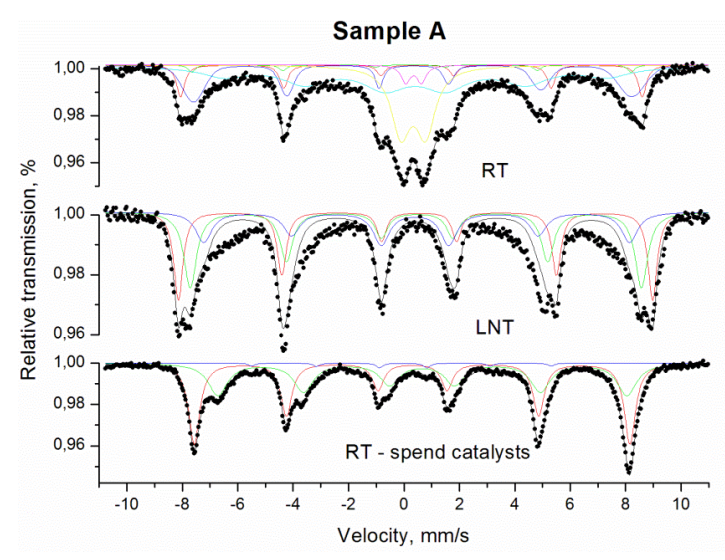

Figure 3. Mössbauer spectra of Sample A (Fe-Co/AC) at RT, at LNT and after WGSR catalytic test at RT.

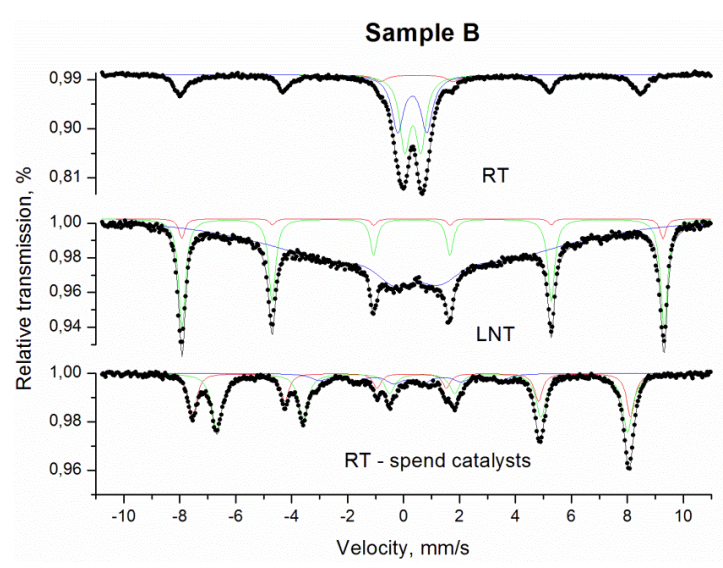

Figure 4. Mössbauer spectra of Sample B (Fe-Cu/AC) at RT, at LNT and after WGSR catalytic test at RT.

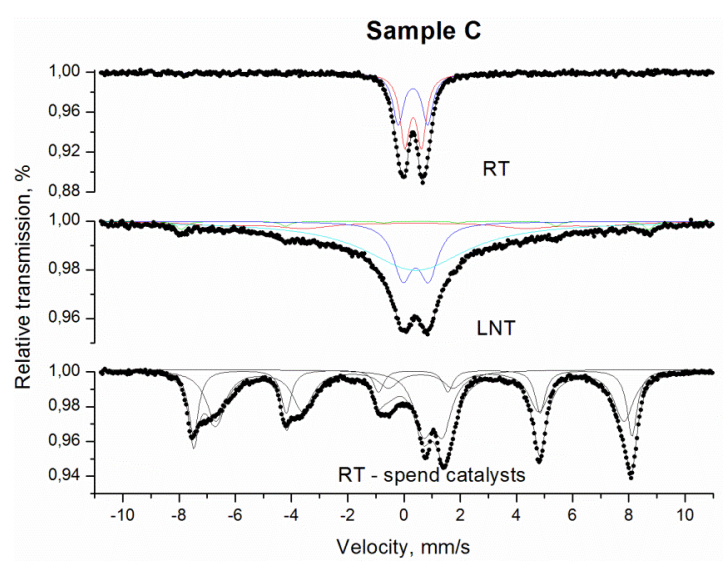

Figure 5. Mössbauer spectra of Sample C (Fe-Mn/AC) at RT, at LNT and after WGSR catalytic test at RT. conditions. Changes are registered in phase composition of materials (Figures 3-5 and Table 1). The calculated values of sextet lines lead to conclusion of $\mathrm{Fe}_{3} \mathrm{O}_{4}$ particles formation having characteristic two subspectra of tetrahedrally coordinated $\mathrm{Fe}^{3+}$ and octahedrally coordinated mixed valence $\mathrm{Fe}^{2.5+}$ component. Their relative component weights indicate the presence of stoichiometric magnetite in case of Sample B and nonstoichiometric magnetite in Samples $A$ and $C$. In all cases $H_{\text {eff }}$ of sextet components have smaller values than those of bulk material (Table 1 ). This shows that under the reaction conditions iron oxides have been reduced to magnetite and this supported magnetite phase preserve initial high dispersion in reaction conditions. So nanosized magnetite is the main catalyst steady state phase formed during the reaction conditions, which explains the observed very good catalytic activity in studied high temperature WGSR. Differences in phase composition of materials can be interpreted as responsible of different catalytic behavior. It can be seen the formation of small quantity of metal, carbide or wustite phase in spent catalysts (Table 1). The impact of the second ion $\left(\mathrm{Co}^{2+}, \mathrm{Cu}^{2+}\right.$ and $\mathrm{Mn}^{2+}$ ) should be taken into account also. It can be seen on Figure 6 about two time higher CO conversion degree of copper-containing sample in comparison to cobalt and manganese especially at low temperatures. This highest catalytic activity can be explained by consideration that under the reaction conditions the catalyst is partially reduced to a finely disperse metallic copper, which was established as the working phase at a low-temperature WGSR. On the other hand the presence of $\mathrm{Cu}$ in the sample considerably decreases the reduction temperature of $\mathrm{Fe}_{2} \mathrm{O}_{3}$ to magnetite $\left(\mathrm{Fe}_{3} \mathrm{O}_{4}\right) \cdot{ }^{[2-3]}$ The registered low catalytic activity in case of $\mathrm{Mn}$-containing material is probably due to the catalyst over-reduction. This leads to formation of FeO in Sample C, which was detected in the spend catalyst analysis.

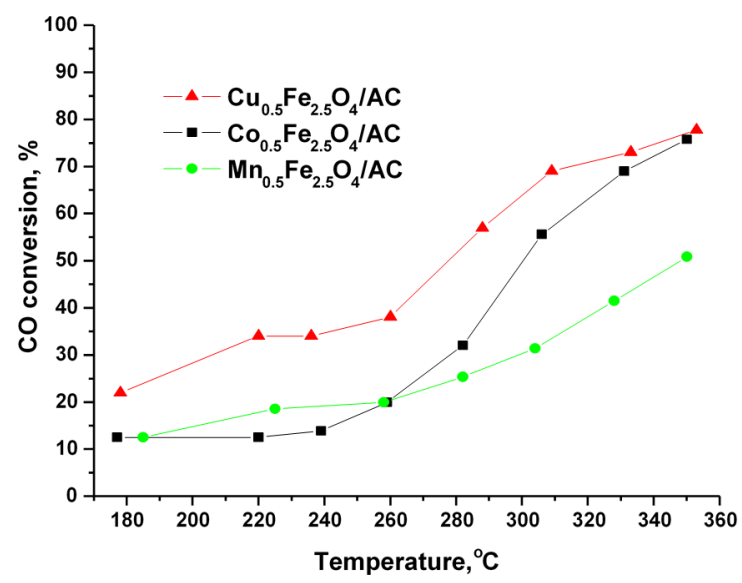

Figure 6. WGSR catalytic activity of the samples expressed as CO conversion. 
Table 1. Mössbauer hyperfine parameters of spectra components of ferrite/AC samples measured at room temperature (RT) and at liquid nitrogen temperature (LNT).

\begin{tabular}{|c|c|c|c|c|c|c|}
\hline Sample & Components & $\mathrm{IS} / \mathrm{mm} \mathrm{s}^{-1}$ & $\mathrm{QS} / \mathrm{mm} \mathrm{s}^{-1}$ & $H_{\text {eff }} / \mathrm{T}$ & $\begin{array}{c}\text { FWHM / } \\
\mathrm{mm} \mathrm{s}^{-1}\end{array}$ & $G / \%$ \\
\hline \multirow{6}{*}{$\begin{array}{l}\text { Sample A - RT } \\
\mathrm{CO}_{0.5} \mathrm{Fe}_{2.5} \mathrm{O}_{4} / \mathrm{AC}\end{array}$} & Sxt $1-\mathrm{Fe}^{3+}$ Hematite & 0.37 & -0.21 & 51.8 & 0.35 & 10 \\
\hline & Sxt $2-\mathrm{Fe}^{3+}$ - octa & 0.24 & 0.05 & 49.3 & 0.31 & 5 \\
\hline & Sxt $3-\mathrm{Fe}^{3+}$ - tetra & 0.34 & -0.04 & 49.2 & 0.33 & 19 \\
\hline & Sxt $4-\mathrm{Fe}$ - spinel, CME & 0.41 & 0.02 & 42.8 & 1.94 & 40 \\
\hline & Dbl $1-\mathrm{SPM}$ & 0.35 & 0.57 & - & 0.39 & 6 \\
\hline & $\mathrm{Dbl} 2-\mathrm{SPM}$ & 0.34 & 0.90 & - & 0.84 & 20 \\
\hline \multirow{4}{*}{$\begin{array}{l}\text { Sample A - LNT } \\
\mathrm{Co}_{0.5} \mathrm{Fe}_{2.5} \mathrm{O}_{4} / \mathrm{AC}\end{array}$} & Sxt $1-\mathrm{Fe}^{3+}$ Hematite & 0.48 & -0.15 & 53.2 & 0.39 & 25 \\
\hline & Sxt $2-\mathrm{Fe}^{3+}-$ octa & 0.46 & -0.05 & 50.6 & 0.55 & 29 \\
\hline & Sxt $3-\mathrm{Fe}^{3+}$ - tetra & 0.36 & -0.10 & 43.6 & 1.89 & 24 \\
\hline & Sxt 4 - Fe - spinel, CME & 0.42 & 0.06 & 47.7 & 0.70 & 22 \\
\hline \multirow{3}{*}{$\begin{array}{l}\text { Sample A after catalytic test - RT } \\
\qquad \mathrm{Co}_{0.5} \mathrm{Fe}_{2.5} \mathrm{O}_{4} / \mathrm{AC}\end{array}$} & Sxt $1-\mathrm{Fe}^{3+}$ - tetra & 0.30 & -0.02 & 48.9 & 0.48 & 52 \\
\hline & Sxt $2-\mathrm{Fe}^{2.5+}-$ octa & 0.66 & 0.01 & 45.9 & 0.83 & 46 \\
\hline & Sxt $3-\mathrm{Fe}-$ metal phase & -0.05 & -0.06 & 49.2 & 0.29 & 2 \\
\hline \multirow{3}{*}{$\begin{array}{l}\text { Sample B - RT } \\
\mathrm{Cu}_{0.5} \mathrm{Fe}_{2.5} \mathrm{O}_{4} / \mathrm{AC}\end{array}$} & Sxt $1-\mathrm{Fe}^{3+}$ Hematite & 0.36 & -0.21 & 51.0 & 0.54 & 28 \\
\hline & Dbl $1-$ SPM & 0.33 & 0.58 & - & 0.43 & 37 \\
\hline & Dbl 2 - SPM & 0.31 & 1.04 & - & 0.51 & 35 \\
\hline Sample B - LNT & Sxt $1-\mathrm{Fe}^{3+}$ Hematite & 0.48 & 0.39 & 53.5 & 0.29 & 27 \\
\hline $\mathrm{Cu}_{0.5} \mathrm{Fe}_{2.5} \mathrm{O}_{4} / \mathrm{AC}$ & Sxt $2 \mathrm{Fe}$ - spinel, CME & 0.47 & -0.02 & 30.2 & 1.51 & 73 \\
\hline \multirow{3}{*}{$\begin{array}{l}\text { Sample B after catalytic test - RT } \\
\qquad \mathrm{Cu}_{0.5} \mathrm{Fe}_{2.5} \mathrm{O}_{4} / \mathrm{AC}\end{array}$} & Sxt $1-\mathrm{Fe}^{3+}$ - tetra & 0.29 & 0.00 & 48.6 & 0.34 & 30 \\
\hline & Sxt $2-\mathrm{Fe}^{2.5+}-$ octa & 0.67 & 0.00 & 45.6 & 0.43 & 54 \\
\hline & Sxt $3-\mathrm{Fe}$ - carbide phase & 0.199 & 0.065 & 20.14 & 0.70 & 16 \\
\hline Sample C - RT & Dbl 1 - SPM & 0.33 & 0.59 & - & 0.41 & 55 \\
\hline $\mathrm{Mn}_{0.5} \mathrm{Fe}_{2.5} \mathrm{O}_{4} / \mathrm{AC}$ & Dbl $2-S P M$ & 0.32 & 1.04 & - & 0.45 & 45 \\
\hline \multirow{4}{*}{$\begin{array}{l}\text { Sample C - LNT } \\
\mathrm{Mn}_{0.5} \mathrm{Fe}_{2.5} \mathrm{O}_{4} / \mathrm{AC}\end{array}$} & Sxt 1 - Fe - spinel, CME & 0.48 & -0.08 & 51.6 & 0.41 & 3 \\
\hline & Sxt 2 Fe - spinel, CME & 0.33 & -0.11 & 42.3 & 1.92 & 14 \\
\hline & Dbl $1-$ SPM & 0.42 & 0.92 & - & 0.81 & 24 \\
\hline & Dbl 2 - SPM & 0.43 & 0.00 & - & 2.8 & 59 \\
\hline \multirow{3}{*}{$\begin{array}{l}\text { Sample C after catalytic test - RT } \\
\qquad \mathrm{Mn}_{0.5} \mathrm{Fe}_{2.5} \mathrm{O}_{4} / \mathrm{AC}\end{array}$} & Sxt $1-\mathrm{Fe}^{3+}$ - tetra & 0.32 & -0.02 & 48.5 & 0.43 & 30 \\
\hline & Sxt $2-\mathrm{Fe}^{2.5+}$ - octa & 0.61 & -0.03 & 45.1 & 0.85 & 48 \\
\hline & $\mathrm{Dbl}-\mathrm{FeO}$ & 1.03 & 0.70 & - & 0.78 & 22 \\
\hline
\end{tabular}

\section{CONCLUSIONS}

Series of supported on activated carbon ferrite materials $\mathrm{Me}_{0.5} \mathrm{Fe}_{2.5} \mathrm{O}_{4} / \mathrm{AC}\left(\mathrm{Me}=\mathrm{Co}^{2+}, \mathrm{Cu}^{2+}\right.$ and $\left.\mathrm{Mn}^{2+}\right)$ was prepared using co-precipitation method and low temperature heat treatment in nitrogen atmosphere at $400{ }^{\circ} \mathrm{C}$. Room and low temperature Mössbauer spectroscopy were combined with analysis of powder X-ray diffraction to investigate the chemical composition, stoichiometry, particle size and dispersity of supported phases formed after co-precipitation, heating and catalytic tests. It was obtained that iron oxide catalysts with a high dispersion are synthesized, containing magnetite and hematite. Under the studied reaction conditions the supported phases are partially reduced. Nanosized magnetite is the

main catalyst steady state phase and this explains observed very good catalytic activity in studied high temperature WGSR. The formation of small quantity of metal, carbide or wustite phase in spent catalysts and influence of the second ion $\left(\mathrm{Co}^{2+}, \mathrm{Cu}^{2+}\right.$ and $\left.\mathrm{Mn}^{2+}\right)$ are responsible for differences in catalyst behavior. The WGSR activity order was as follows: $\mathrm{Cu}_{0.5} \mathrm{Fe}_{2.5} \mathrm{O}_{4} / \mathrm{AC}$ > $\mathrm{Co}_{0.5} \mathrm{Fe}_{2.5} \mathrm{O}_{4} / \mathrm{AC}>\mathrm{Mn}_{0.5} \mathrm{Fe}_{2.5} \mathrm{O}_{4} / A C$. Catalytic tests demonstrated very promising results and potential application of studied samples due to their cost-effective composition.

Acknowledgment. The financial support of the National Science Fund, Ministry of Education and Sciences of Bulgaria by Contracts DFNI E-01/07/2012 and DFNI E-02/2/2014 is appreciated. 


\section{REFERENCES}

[1] D. L. Trimm, Appl. Catal. A: General 2005, 296, 1.

[2] A. Khan, P. Chen, P. Boolchand, P. G. Smirniotis, J. Catal. 2008, 253, 91.

[3] A. Khan, P. G. Smirniotis, J. Molec. Catal. A: Chemical 2008, 280, 43 .

[4] C. Martos, J. Dufour, A. Ruiz, Int. J. Hydrogen Energ. 2009, 34, 4475.

[5] A. Luengnaruemitchai, S. Osuwan, E.Gulari, Catal. Commun. 2003, 4, 215.

[6] U. Schwertmann, R. M. Cornell, Iron Oxides in the Laboratory: Preparation and Characterization, Wiley-VCH Verlag, Weinheim, 2000
[7] G. A. Sawatsky, F. van der Woude, A. H. Morrish, Phys. Rev. 1969, 183, 383.

[8] C. M. Srivastava, S. N. Shringi, M. V. Babu, Phys. Stat. Sol. (a) 2006, 65, 731.

[9] M. F. F. Lelis, J. D. Fabris, W. N. Mussel, A. Y. Takeuchi, Mater. Res. 2003, 6(2), 145.

[10] G. K. Williamson, W. H. Hall, Acta Metall. 1953, 1, 22.

[11] A. Van Der Kraan, Phys. Status Solidi A 1973, 18, 215.

[12] G. A. Sawatzky, F. Van Der Woude, A. H. Morrish, Phys. Rev. 1969, 187, 747.

[13] J. W. Niemantsverdriet, A. M. Van der Kraan, W. N. Delgass, M. A. Vannice, J. Phys. Chem. 1985, 89, 67.

[14] F. Bødkert, S. Mørup, C. A. Oxborrow, S. Linderoth, M. B. Madsen, J. W. Niemansverdriet, J. Phys.: Condens. Matter. 1992, 4, 6555. 